\title{
Manual do entrevistado
}

Nelson Vitiello*

É comum ouvirem-se, expressas por profissionais, queixas sobre a imprensa. Tais reclamações são comuns a todas as áreas, mas ainda mais freqüentes entre os que, de alguma forma, lidam com aspectos ligados às condições de exercício da sexualidade, tema tão em moda na atualidade. São usuais protestos tais como "fui mal interpretado", "o repórter me tomou horas para no final serem divulgados apenas alguns segundos da entrevista", "publicou-se apenas uma de minhas frases, o que resultou numa distorção do sentido", e várias outros.

A tal ponto avultam essas críticas aos profissionais da comunicação que é de se perguntar se vale mesmo a pena que se abra mão de um precioso tempo de lazer ou de trabalho para atender às solicitações cada vez mais freqüentes de opiniões e entrevistas. Desde já é importante ressaltar: vale sim! Apresentaremos a seguir nossos pontos de vista sobre o tema, originados de alguma experiência pessoal e de observações de profissionais da área.

* Ginecologista e Terapeuta Sexual. Doutor em medicina pela USP. Presidente da Sociedade Brasileira de Estudos em Sexualidade Humana (SBRASH).

Recebido em 18.03.00

Aprovado em 05.04 .00 


\section{PORQUE VALE A PENA DAR ENTREVISTAS}

Inicialmente importa lembrar que os meios de comunicação representam importante fonte de consulta e, em graus variáveis, gozam de credibilidade dos diferentes segmentos da sociedade. Assim, uma notícia num veículo conceituado tem uma capacidade de penetração e de formação de opinião muito relevantes em nossa cultura. Se considerarmos que uma das funções sociais do exercício de qualquer profissão é a transmissão dos conhecimentos ao público em geral, devemos levar em conta de que não se pode abrir mão dos meios de comunicação de massa para essa tarefa.

Um profissional, por mais que se dedique à sua atividade assistencial, de pesquisa ou de comunicação científica para outros profissionais, não estará cumprindo todo o seu dever se não se esforçar para levar tais conhecimentos também aos leigos no assunto. Isso é ainda mais verdadeiro quando diz respeito à temas ligados ao exercício da sexualidade, que tanto tem mobilizado as pessoas.

Se você, que é um profissional competente, informado e ético não der entrevistas, outro o fará. E mesmo que profissional nenhum se disponha a ser entrevistado, isso não evitaria que os meios de comunicação falassem do assunto, visto que a demanda por informação pelos usuários dos meios de comunicação é imensa.

É claro que se profissionais competentes se recusarem a fornecer a versão mais fiel, os vazios de informação gerarão versões ou rumores que serão divulgados, sem o seu ponto de vista.

\section{TENDÊNCIAS DOS MEIOS DE COMUNICAÇÃO MODERNOS}

É importante que os profissionais da área da ciência tenham presentes algumas das características dos modernos meios de comunicação, para melhor entendê-los.

Assim, mundialmente, busca-se uma cada vez maior liberdade de imprensa. Embora em alguns países existam ocasionais "recaídas" em termos de censura, a tendência mundial é mesmo para uma cada vez maior liberdade de expressão nos meios de comunicação.

Existe, além disso, um claro direcionamento para, quando possível, execução do chamado "jornalismo investigativo". Se bem que, de maneira geral, a maioria dos meios ainda não está bem aparelhada e equipada para um jornalismo investigativo eficiente e atuante, a tendência nesse rumo é clara.

O que os meios de comunicação buscam, genericamente falando, são notícias que gerem repercussão, que sejam analisadas também por outros 
meios de comunicação. Assim, é freqüente que quando um veículo apresenta uma notícia sobre um fato qualquer, o mesmo fato seja repetido ad nauseam em outros meios. Os temas atualmente em moda, tais como sexualidade, meio ambiente, consumo, qualidade de vida, uso da internet, e vários outros tendem a ser repetidos, sob seus vários enfoques, nos meios de comunicação.

Deve-se ainda ter em conta que na imensa maioria das vezes os jornalistas estão interessados em temas que digam respeito à vida cotidiana das pessoas, visto serem tais temas os mais buscados pelos consumidores. Assim, informações sobre a descoberta de vida em outra galáxia, embora assunto de grande interesse científico, perde em importância (avaliada pelas chamadas ou manchetes) para uma notícia sobre a Seleção Brasileira de Futebol, por exemplo.

Soma-se a essa circunstância o fato de que as notícias tiradas dos profissionais (médicos, cientistas, etc.) são as vezes as únicas que podem trazer um minuto de boas notícias em um noticiário de TV de uma hora. Assim, como as pessoas buscam também boas notícias, os profissionais são sempre procurados, observando-se mesmo uma repetição temática em diversos programas. Para citar um exemplo, um dos mais famosos programas de televisão, o "Fantástico", traz sempre uma matéria de saúde.

Em resumo, os meios de comunicação não buscam apenas veicular informações, mas sim fatos que possam ser notícia, aqui compreendendose essa palavra como algo que chame a atenção de leitores, ouvintes ou espectadores. De maneira geral, tendo em vista a precariedade do espaço ou do tempo disponível, o que os jornalistas desejam realmente é que o entrevistado formule frases curtas e de efeito contundente. A partir disso é que o Editor, seja do meio impresso, da rádio ou da TV, criarão títulos ou manchetes julgadas "chamativas".

E importante que os profissionais das áreas do saber se conscientizem de que, exceto em situações extraordinárias, seu depoimento ou entrevista será reduzido. Se o meio de comunicação considerado for o rádio ou a TV, essa redução será ainda maior. Habitualmente as chefias de reportagem encomendam dos repórteres entrevistas de no máximo três minutos que, ao serem editadas, geram noticias com duração em torno de quinze segundos. Assim, é importante que o entrevistado seja capaz de fazer intensa síntese, para que não se decepcione quando sua entrevista for ao ar. Além disso, como a tendência atual dos meios de comunicação é de, sempre que possível, ouvir o maior número de fontes, ainda mais se existirem controvérsias sobre o tema, o tempo final de cada entrevistado no produto final da reportagem fica bastante encurtado.

Tem-se observado, além disso, que os meios de comunicação estão lidando com a temática apresentada, em especial no que diz respeito à fatos ligados à sexualidade, com uma competência crescente. Já existem, em diversos órgãos de imprensa (jornais e revistas, principalmente), jornalistas que 
aos poucos vão se especializando nesses assuntos, sendo de esperar que deixe de ter razão de ser, em breve, a queixa freqüentemente formulada por entrevistados, de que o jornalista não consegue captar o que ele diz. Outros meios de comunicação, como a TV e o rádio, não estão tão avançados, sendo comum que um mesmo profissional de imprensa cubra temas os mais diversos.

No que diz respeito à internet essa especialização está ficando bem clara. Diversos sites já contam com profissionais especializados.

Devemos ainda nos conscientizar de ser nossa obrigação levar à sociedade os conhecimentos que as pessoas necessitam. Essa comunicação não deve ficar apenas no terreno do científico, do racional, visto que as pessoas tendem a não introjetar o que lêem ou ouvem apenas como informação. Para que o fato atinja realmente o público é importante que a mensagem passe também pelo emocional. Por isso mesmo não devemos nos zangar quando um meio de comunicação apela para recursos que julgamos "pouco técnicos", tais como depoimentos de pessoas que tem ou tiveram o problema ou a condição de que se está tratando. A entrevista de um médico, por exemplo, sobre as conseqüências de uma gestação indesejável na adolescência atingem muito mais as pessoas e leva-as a se preocuparem com a necessidade de programas de planejamento familiar se, além do depoimento do técnico, houver o de uma adolescente que está ou esteve grávida.

\section{DESCONFIANÇAS MÚTUAS}

Os profissionais tendem sempre a achar que os meios de comunicação de massa são sensacionalistas e que os seus representantes, os repórteres ou apresentadores, não entendem de nada e por isso mesmo escrevem ou dizem o que primeiro aparecer. Além disso, meios de comunicação e repórteres são acusados de serem manipulados por grupos de pressão ou por interesses financeiros.

Os profissionais da imprensa, por seu lado, julgam serem os profissionais uns egoístas que não compartilham dados, escondem a verdade e buscam só um tratamento favorável, não gostando de falar aos jornalistas.

Claro que em graus mais ou menos intensos tais opiniões tem sua razão de ser. Tanto uns quantos outros se tornam merecedores dessas afirmativas, em certas situações. No entanto, vale dizer aos profissionais que os jornalistas representam um segmento social diverso daquele ao qual estão habituados. Os profissionais da imprensa tem valores, cultura emoções, personalidades, experiências e expectativas diversas da de seus entrevistados, o que ocasionalmente gera choques.

Devemos lembrar que um jornalista não um amigo, nem um inimigo, é apenas um profissional de outra área, tentando cumprir suas funções e, como tal, merecedor de todo nosso respeito. Não se pode esquecer desse relevante fato pois, muitas vezes, temos a tendência a ver nele um inimigo, pronto a nos 
pegar em alguma armadilha, a publicar coisas que não dissemos, etc. Tenhamos claro serem os jornalistas apenas isso, profissionais como nós - embora de outra área - tentando cumprir suas tarefas, como nós.

Cada meio de comunicação, ou mesmo cada jornalista, organiza uma lista de possíveis entrevistados em determinado tema. Tais pessoas são mais amiúde consultadas, até mesmo para indicar outras, de áreas específicas. Somos assim, para esses jornalistas, apenas "fontes". Como tal, somos classificados pela facilidade de acesso, pela disponibilidade em fornecer entrevistas, pela amplidão dos conhecimentos, pela confiabilidade. Em outras palavras, para que sejamos considerados "boas fontes", devemos ser acessíveis e fornecer informações precisas, concisas, suficientes, relevantes e responsáveis.

Evidentemente, existem situações em que o profissional de imprensa interpreta mal nossas opiniões, nos corta períodos importantes ou mesmo distorce o que dizemos. Não temos defesa contra isso, a não ser em casos extremos, onde podemos exigir direito de resposta ou de contestação. Alguns veículos de comunicação, como o jornal "A Folha de São Paulo", por exemplo, tem mesmo uma sessão "Erramos", onde os enganos mais flamantes podem ser corrigidos. No geral, no entanto, nossas reclamações acabam ficando conosco mesmo, que tendemos a generalizar e achar que "todos são iguais"...

Deve-se lembrar ainda que o jornalista, freqüentemente, não tem o poder de decisão final, que cabe quase sempre a um editor, ao qual raramente temos acesso.

A única defesa possível contra a insatisfação, nos casos menos graves, é que também nós organizemos uma lista de "receptores" de notícias, tais como eles têm as suas listagens de "fontes". Devemos, com o passar do tempo e a aquisição de experiência, ir selecionando os jornalistas para os quais demos entrevistas ou depoimentos. Se algum repórter distorceu ou subaproveitou o que dissemos, se a entrevista não ficou de nosso agrado, devemos deixar de dar entrevistas para esse profissional da imprensa, o que evitará futuros dissabores.

Além disso, quando se trata de entrevistas concedidas ao rádio ou à TV, o perfil do programa e até o do entrevistador já é, em geral conhecido. Assim sendo, programas popularescos jamais tratarão assuntos técnicos com a seriedade que julgamos que eles merecem. A solução, nesses casos, é recusar-se (polidamente, sempre) a comparecer a tais programas.

\section{PREPARO PARA A ENTREVISTA}

Quando somos chamados a dar um depoimento ou uma entrevista a um meio de comunicação, devemos considerar alguns pontos muito relevantes. 
O primeiro deles é o dever de nos informar-mos sobre as características do meio de comunicação e, se possível, da sessão ou do programa onde nossa entrevista será veiculada. Quando for cabível e viável, até mesmo sobre o repórter ou o entrevistador devemos colher informações. Não é raro que, por não conhecermos bem o estilo e o ritmo do programa, sejamos surpreendidos por algum entrevistador mais agressivo ou afoito.

Outro ponto relevante sobre o qual temos que nos informar, no caso de entrevistas pelo rádio ou TV é se seremos o único profissional da área presente ou se existirão outros. Nesse caso, quando possível, devemos procurar saber quem são eles, pois esse conhecimento pode ser valioso. Se a entrevista é para um meio escrito, busque também saber se serão ouvidos outros profissionais. Seja pontual e atento.

A seguir, procure colocar-se no lugar do repórter, entrevistador ou editor da entrevista. Compreenda a necessidade dele de tirar de você informações de interesse jornalístico. Se necessário, vá munido de material de apoio, para não titubear quanto a informações numéricas, por exemplo. Os profissionais das áreas ditas "humanas" tem conhecida ojeriza por números. Julgam sempre que as exigências dos repórteres em afirmações baseadas em números são descabidas e pouco expressivas. No entanto, mais uma vez colocando-se no lugar dele, é claro que dizer que "a disfunção erétil é muito comum" não tem a mesma força que afirmar claramente que " $30 \%$ dos homens adultos são disfuncionais eréteis". Dizer que "a gestação indesejável entre adolescentes atinge números alarmantes" perde de longe para "o IBGE registra 600 mil partos de adolescentes por ano no Brasil”. Lembre-se que uma afirmação alicerçada em números dará mais sustentação à sua idéia. Dê preferência, quando cabível, às percentagens, que são de fácil entendimento e memorização. Ainda mais importante, fuja de detalhamentos decimais. Arredonde os números. Nunca diga " $59,7 \%$ ", diga "quase $60 \%$ ".

Para otimizar sua participação, é importante que já leve a mensagem que deseja passar bem definida em sua mente. Lembre-se de que o tempo disponível é sempre menor do que aquele que você julga necessário. Por isso, quando possível, leve definidas três idéias claras. Isso mesmo, só três são o suficiente, pois caso o tempo sobre, o próprio repórter se encarregará de fazer o tema girar em torno de suas três idéias.

Prepare-se para responder às inevitáveis perguntas a queima-roupa, se a entrevista for no rádio ou na TV. Pense antecipadamente nas respostas que dará se for questionado sobre os " $6 \mathrm{~W}$ " (What? Who? When? Where? Why? HoW?). Treine as respostas, se possível, com a esposa, um filho, sobrinho ou amigo. Lembre-se que, como a entrevista será dirigida a um público não técnico, até mesmo um adolescente com espírito crítico pode fornecer-lhe valiosas sugestões sobre a comprensibilidade ou não de sua apresentação. 


\section{ATUANDO NA ENTREVISTA: GENERALIDADES VÁLIDAS PARA TODOS OS MEIOS DE COMUNICAÇÕES}

Embora o "dono" do roteiro não seja você, não se intimide nem deixe de, quando possível, tomar a iniciativa. Essa iniciativa pode ser expressa, por exemplo, no levantamento de ângulos da questão que até então escaparam ao entrevistador. Apresente, desde o início, clara e sucintamente seus pontos de vista sobre o tema em pauta, em não mais que trinta segundos. Deixe ao entrevistador a tarefa de cobrir os espaços, se isso for necessário, pois essa é a função dele.

Nas entrevistas concedidas ao rádio ou à televisão é muito importante que você se informe sobre se ela será gravada ou ao vivo. As participações ao vivo, embora geralmente assustem mais os iniciantes, tem a clara vantagem de que não será possível cortar nada do que você estiver dizendo, isto é, não são entrevistas passíveis de serem "editadas".

Não responda baseado em suposições. Você não está ali para "achar" nada, você está ali para "afirmar" fatos! Fuja por isso mesmo das suposições, pois elas freqüentemente o levarão a alguma armadilha ou contradição, que em certas situações podem ser exploradas por entrevistadores menos bem intencionados. Além disso, a não ser que seja diretamente solicitado, evite manifestações de cunho político, especialmente as de apoio ou reprovação a atuação de homens públicos.

Nunca, mas nunca mesmo, polemize com o entrevistador ou com outros convidados, que eventualmente levam a discussão além dos limites científicos para o qual você está preparado. Como (especialmente a TV) leva mais em conta a emoção do que a razão, não é incomum que o profissional desavisado acabe sendo envolvido em uma discussão emocional, onde só tem a perder. Se discordar de alguma afirmação do apresentador ou de algum convidado, ou de opiniões trazidas à discussão, diga clara e firmemente que discorda, buscando no entanto não exprimir sua discordância de forma ofensiva. Diga sempre "não é bem assim" ou "essa é uma versão que não é unanimemente aceita", em vez de dizer "isso é uma mentira!". Importa também que não se sinta agredido pelas afirmações do entrevistador. Lembre-se que ele é apenas um jornalista e que, pela formação, você é quem tem obrigação de estar com a verdade. Seja compreensivo com ele.

Lembre-se que o público para o qual vai falar é constituído fundamentalmente de não técnicos; assim, fuja de expressões técnicas ou palavras pouco comuns. Em outras palavras, em vez de "hebdomadário", diga "semanal"... Afinal, você está num meio de comunicação, não num meio acadêmico.

Por isso mesmo, use linguagem clara e acessível, evite usar jargão técnico ou construir frases complicadas (a ordem indireta é um pecado!). 
Sempre que cabível use uma analogia ou conte um "causo" para explicar seu ponto de vista.

Assegure-se, na medida do possível, que será entendido. Nunca fale imaginando que o repórter ou o público domina o assunto. Lembre-se de que você tem dois importantes compromissos. O primeiro, óbvio, é com o campo científico, de não transmitir nada que não seja considerado cientificamente verídico. O segundo, no campo social, é esclarecer o tema proposto. Por isso mesmo, assegure-se de que será bem compreendido.

Evite o humor fora de lugar. No entanto, não é necessário ficar o tempo todo carrancudo. Sorrisos são sempre agradáveis. Seja cortềs, correto e honesto. Mesmo que não diga tudo o que sabe, saiba tudo o que diz!

Evite também o uso abusivo da primeira pessoa do singular. É sempre mais simpático referir-se a "nós", visto que - a não ser em casos excepcionais - você está representando uma corrente de pensamento.

Destaque, antes de tudo, os ângulos de interesse geral do problema proposto e só depois desça às particularidades. Usando essa técnica, a audiência (ou os leitores) assumirão melhor suas idéias, tomando-as mesmo como suas.

Outro aspecto importante é que nada, absolutamente nada, deve ser considerado como em "off"! Achar que, a seu pedido, o repórter vai deixar de lado uma informação importante, ou um fato relevante, é uma inocência imperdoável. Mesmo que ele jure sigilo, é mais prudente precaver-se e não exarar opiniões que não deseje sejam divulgadas. E principalmente, quer em público quer em (pretenso) off, nunca desqualifique uma instituição ou pessoa. Isso é deselegante, antipático e contraproducente. Você não está ali para falar mal de ninguém, ou para lavar roupas sujas de antigas querelas acadêmicas, você está ali para informar, educar e comunicar suas idéias e posições. Para fazer isso não é necessário usar "bodes expiatórios"...

Caso a entrevista derive para aspectos que não são de sua área de conhecimento, ou que sejam solicitados dados que não possui, diga clara e honestamente que não tem essas informações, podendo até mesmo proporse a complementá-las depois. Não "chute".

\section{PECULIARIDADES DE ENTREVISTAS VIA TV}

As entrevistas pela TV são as que exigem mais flexibilidade de espírito e maior grau de preparo, especialmente se são "ao vivo". Além das recomendações gerais acima descritas, algumas outras recomendações importantes:

1. Acostume-se com o ambiente. Alguns entrevistados ficam com a aparência de ratos tímidos. Dirija-se nominalmente ao apresentador. 
2. O mais comum é que para essas entrevistas ao vivo ou gravadas em estúdios exista necessidade de um mínimo de maquiagem, ao menos um pó para tirar o brilho da pele, especialmente para quem a tem oleosa. Esse ritual, que as vezes constrange os iniciantes, é perfeitamente natural, e faz parte da rotina. Os estúdios tem profissionais especializados e você não terá incômodo maior do que ter que lavar o rosto após a entrevista.

3. Cuide de sua aparência. Vista-se adequadamente. Você não foi chamado a desfilar, mas mesmo assim é importante que sua aparência traduza sua importância. Cada canal, por misteriosos motivos, tem recomendações sobre não usar determinadas cores, que segundo o jargão técnico "estouram o vídeo". Informe-se com antecedência, quando for convidado, qual a cor mais adequada para aquele Canal. Em geral, o branco é a cor que mais freqüentemente se solicita aos convidados não usarem.

4. Seja autêntico. Estilos são pessoais e, mesmo com longo e intensivo treinamento, você jamais conseguirá imitar com perfeição o Jô Soares...

5. Os programas de entrevistas, muito freqüentemente, exibem temas polêmicos, chamando para isso profissionais com visões diferentes. Exatamente por isso são tão importantes as recomendações já feitas sobre a coleta de informações a respeito do tema do programa e eventuais outros participantes.

6. Fale claramente e com segurança. Antes de iniciar a entrevista, é comum que os técnicos de som testem os microfones com você. Tente fazer com que sua voz e sua entonação sejam o mais possível parecidas com sua voz natural.

7. Procure não ficar exageradamente estático. Olhe o maior tempo possível para a câmara, pois isso dá uma impressão "olho no olho" com o espectador que transmite segurança.

8. Cuidado com a gesticulação. Evite ficar parado o tempo todo, mas fuja da gesticulação excessiva.

9. Olhe para o apresentador, enquanto ele the formula perguntas, e para a câmera quando for responder.

10. O mais importante: A TELEVISÃO TRANSMITE IMPRES$S O \tilde{E S}, \mathrm{NA \tilde {O }}$ RAZÕES! Tenha isso bem presente, durante toda a duração da entrevista.

Existem estudos que demonstram qual o nível de fixação de cada item na memória do público, na TV:

$\begin{array}{ll}\text { Linguagem corporal } & 70 \% \\ \text { Voz, tom, ênfase } & 20 \% \\ \text { Conteúdo } & 10 \%\end{array}$


Fica óbvio assim ser o conteúdo de sua entrevista o que menos vai ficar na memória do público. Além disso, no que diz respeito à televisão, é importante lembrar que, por vários fatores que não cabe aqui discutir, $65 \%$ das pessoas, atualmente, recebe informações e mensagens exclusivamente pela televisão. Assim, fica óbvio o interesse de que se use bem esse meio de comunicação.

\section{PECULIARIDADES DE ENTREVISTAS VIA RÁDIO}

A entrevista via rádio, embora guarde bastante semelhança com as para a televisão, tem também suas peculiaridades.

Evidentemente, pela própria natureza do meio, a dicção, o tom de voz e clareza de expressão assumem ainda mais importância, visto que não podem, como na TV, serem complementados pela expressão corporal. Sua voz deve ser entoada com limpidez, firmeza e convicção. Evite tiques verbais do tipo "bem...", ou "hammmm...".

No entanto, ainda por essa falta do visual, no rádio é mais cabível que você leve material de apoio (textos, gráficos, anotações), se achar que isso poderá auxiliá-lo. Discipline-se no entanto para ser objetivo, pois se abusar das anotações vai ter dificuldades em encontrar a referência desejada com rapidez.

Procure fugir de embaraçosos silêncios, tendo sempre bem organizadas as idéias do que e como vai dizer as coisas. Dirija-se ao locutor pelo nome. Cumprimente os ouvintes e deles se despeça apenas se para isso for convidado.

E lembre-se: se a entrevista for gravada pode ocorrer que, por necessidade de adequação da programação, parte do que disser seja cortado. Assim, quanto mais direto e objetivo você for, quanto mais sintéticas e expressivas forem suas frases, melhor seguramente sairá a entrevista.

\section{PECULIARIDADES DE ENTREVISTAS EM MEIOS DE COMUNICAÇÃO IMPRESSOS}

Muitas vezes somos chamados a opinar sobre o assunto do momento, até mesmo por via telefônica. Embora isso possa ser mais arriscado, pois o grau de compreensão do repórter pode ser precário, levando mais freqüentemente a distorção de nossas declarações, é uma via muito utilizada, especialmente na redação de jornais diários, onde as edições são sempre "para ontem...”. Partindo do princípio de que há mútuo interesse em conceder entrevistas (sim, pois você está divulgando suas idéias e o jornalista está ganhando a vida), faça um esforço e colabore o mais possível com as datas e horários de fechamento das edições. 
Sempre que possível, procure realizar as entrevistas em sua casa ou consultório, visto que num ambiente que lhe seja familiar você ficará mais a vontade, havendo ainda a vantagem adicional de que o material de apoio que possa precisar estará á mão. Para o bom andamento da entrevista, no entanto, convém que providencie para que não hajam interrupções desnecessárias (telefonemas não urgentes, por exemplo).

Se forem usadas fotos, seja paciente (como essa virtude é necessária!) com o fotógrafo. Tente lembrar que ele está ali apenas cumprindo um trabalho.

Em caso de ser solicitado, permita que a entrevista seja gravada. Isso será até favorável para você, pois facilitará ao repórter a compreensão de suas afirmações.

Mesmo que o clima for descontraído, não baixe a guarda! Esteja sempre atento, pois o mais afável dos repórteres pode ter um editor não tanto e, se você facilitar, ele pode distorcer suas palavras. Lembre-se que geralmente, na maioria dos meios de comunicação escrita, quem escolhe o título da matéria é o editor, que além disso usualmente escreve um "gancho", uma introdução do tema, muitas vezes até mesmo usando parte do que você mesmo declarou...

Embora tenha muita vontade de fazer isso, não peça ao repórter para ver a matéria final antes de a mesma ser publicada, a não ser que ele lhe ofereça essa oportunidade. Esse é um ponto muito sensível desses profissionais, que ficam ofendidos com tais pedidos, interpretados como "falta de confiança". Além disso, seu pedido será inútil na maioria das vezes, pois não será mesmo atendido, alegadando-se posteriormente que "não houve tempo...". Assim sendo, conforme-se e corra o risco. Sempre lhe resta o consolo de que pode, no futuro, se recusar a novas entrevistas, se a atual não sair a contento.

Também para os meios de comunicação impressos existem estudos mostrando o que mais fica na lembrança dos leitores. Segundo esses estudos, o nível de recordação da leitura é o seguinte:

$\begin{array}{lr}\text { Título da matéria } & 62 \% \\ \text { Ilustrações, quadros } & 32 \% \\ \text { Conteúdo } & 6 \%\end{array}$

Como se pode ver, também aqui o conteúdo é o item menos lembrado. Por isso mesmo os profissionais das áreas científicas, habituados a valorizar apenas o conteúdo, tem tanta dificuldade em transmitir suas idéias e opiniões.

\section{QUANDO É O PROFISSIONAL QUE DESEJA DIVULGAR ALGUM FATO}

Ás vezes a situação se inverte e, em vez de ser o repórter a procurar o profissional é este último, ou a instituição que ele representa, que tem algu- 
ma notícia que deseja veicular ao público. A instituição de cursos, as descobertas ou a publicação de livros são os motivos mais comuns para isso.

Se o profissional (ou a instituição que ele representa) dispuserem de um assessor de imprensa, a situação está naturalmente resolvida. No entanto a maioria dos profissionais não conta com os préstimos de uma assessoria. Por isso, apresentamos algumas sugestões que podem facilitar esse trabalho.

Antes de mais nada, devemos deixar de lado os falsos pudores e a sensação de não estarmos sendo éticos. Não há nada de errado em noticiar fatos reais, habilidades realmente possuídas ou descobertas nas quais acreditamos. Se somos competentes em determinada área, por que não dizê-lo? Se editamos um livro que acreditamos ser de boa qualidade, com informações úteis ao público, porque não informar disso à esse público? Afinal, se você não diz quem é, corre o risco de alguém dizer por você...

Esse senso exagerado de que anunciar o que fazemos "não é ético" apenas consegue fazer com que nós, os competentes e sérios, sejamos substituídos pelos aventureiros e charlatães! Por isso, se temos algo que julgamos dever anunciar, devemos perder nossos pruridos moralistas e fazer essa divulgação. Como fazê-lo?

Antes de mais nada é relevante levarmos em conta a chamada "segmentação do mercado", isto é, devemos selecionar o tipo de meio de comunicação que pretendemos usar, levando em conta qual o público alvo que desejamos atingir. Assim, se deseja por exemplo fazer uma campanha sobre hábitos sexuais saudáveis para pessoas na terceira idade, evidentemente você não buscará fazer a divulgação numa revista ou num programa direcionados a adolescentes... Em linhas gerais, é fácil identificar o meio mais adequado para o público desejado. Se tiver dificuldades, pergunte a alguém que pertença a esse público qual o veículo de comunicação mais buscado pelos pares.

Em seguida, devemos levar em consideração qual o volume de informações que desejamos transmitir (auferido por espaço nos meios escritos e por tempo nos audiovisuais). Tal determinação de tempo é de fundamental importância, visto que o custo de nossa divulgação precisa ser sempre considerado pois, mesmo que nós não desembolsemos nada para a divulgação, alguém estará pagando por esse espaço.

Deve-se, a seguir, estabelecer uma estratégia para a comunicação. Será ela única ou segmentada? Faremos a comunicação do que temos a transmitir de uma só vez, ou em partes? Que recursos usaremos? Participação em entrevistas? Forneceremos textos para os meios de comunicação? Usaremos figuras, gráficos, fotos? Claro que para cada comunicação desejada deve ser traçado um planejamento adequado.

A divulgação pode ser feita através de comunicados resumidos, denominados "press release", dirigidos às redações e produções dos meios de comunicação. Tais comunicados, no entanto, não costumam ser muito con- 
siderados pelos editores, tendo em vista o número deles que habitualmente é recebido nas redações.

Por isso, uma vez de posse da idéia do conteúdo que queremos transmitir amadurecida, podemos procurar aquele amigo ou conhecido de um meio de comunicação ou, na falta deste, buscar marcar uma entrevista com o editor ou com o produtor do meio de comunicação escolhido. Importa lembrar que aqui a honestidade de propósitos e a justa avaliação da capacidade própria são de fundamental importância, pois nada fica pior para a imagem de um profissional que anunciar coisas irrealizáveis, ou formular promessas que não podem ser cumpridas. É o caso, por exemplo, da divulgação de um curso. As promessas formuladas aos possíveis inscritos devem ser comprovadamente reais. Em outras palavras, além de continuidade, a divulgação deve primar pela consistência. Não nos esqueçamos de que as pessoas, mesmo as não pertencentes ao meio científico que representamos, tem condições intelectuais de perceber promessas mirabolantes e que a credibilidade deve ser nosso mais prezado atributo.

Lembre-se que um jornalista muito atento e hipoteticamente bem informado, que não convive bem com a idéia de perder uma "matéria" de interesse para algum concorrente. Use isso a seu favor quando desejar divulgar sua notícia.

\section{CONCLUSÕES}

Nós, os profissionais das áreas da pesquisa, do ensino e da assistência devemos nos esforçar para nos adaptarmos às características dos meios de comunicação. Se não o fizermos, estaremos perdendo importantes oportunidades de levar nossos conhecimentos ao público, visto ser ilusória a impressão de que chegaremos a eles e seremos compreendidos sem a utilização adequada dos meios de comunicação de massa. 